\title{
Triol protection with 6-benzoyl-3,4-dihydro-(2H)-pyran $\dagger$
}

\author{
Caroline D. L. Baker, ${ }^{a}$ John Fawcett, ${ }^{b}$ Christopher D. Insley, ${ }^{a}$ Derek S. Messenger, ${ }^{a}$ Claire L. Newland, ${ }^{a}$ \\ Helen L. Overend, ${ }^{a}$ Anup B. Patel, ${ }^{a}$ Mufakhrul Shah, ${ }^{a}$ Bhavna Vara, ${ }^{a}$ Davinder Virdee ${ }^{a}$ and \\ Bernard J. Rawlings*a
}

Received (in Cambridge, UK) 30th November 2004, Accepted 8th February 2005

First published as an Advance Article on the web 17th February 2005

DOI: $10.1039 / \mathrm{b} 418035 \mathrm{f}$

6-Benzoyl-3,4-dihydro-( $2 H)$-pyran will protect 1,2,3-triols such as glycerol as their corresponding spiro-[5-phenyl-3,6,8-trioxabicyclo[3.2.1]octane-4,2'-tetrahydropyran]s and 1,2,4-triols (less efficiently) as the corresponding trioxabicyclo[3.2.2]nonanes; the hexol mannitol is converted into the corresponding bis-protected product.

Ketones (or gem-dimethoxyalkanes) can react with 1,2 or 1,3-diols with acid catalysis to form acetals, and dihydropyrans react with alcohols under similar conditions to form tetrahydropyrans. Ley and co-workers recently introduced bis-dihydropyrans to protect a wide range of 1,2-diols as their dispiroketals, the products being formed were those with maximum anomeric stabilisation at newly formed centres. ${ }^{1}$ The Ley group has exploited the rigid architecture of these 'bispoke' derivatives in subsequent asymmetric reactions, ${ }^{2}$ and exploited the bispoke derivatives of vicinal equatorial carbohydrate diols to tune glycoside reactivity. ${ }^{3}$ Ley and coworkers have also developed 1,2-diketones (as 1,1,2,2tetramethoxy derivatives) as 1,2-diol protecting groups, forming in acidic methanol the corresponding 2,3-dimethoxy-1,4-dioxane. ${ }^{4}$ Reaction with glycerol gave triol protection resulting in 2-methoxy-3,7,8-trioxabicyclo[3.2.1]octane. Reaction with vicinal equatorial carbohydrate diols resulted in a glycosidation reactivity

$†$ Electronic supplementary information (ESI) available: experimental and X-ray diffraction data. See http://www.rsc.org/suppdata/cc/b4/b418035f/ *bjr2@le.ac.uk tuning effect between that of the corresponding benzylated and benzoylated systems. ${ }^{5}$

In contrast to that of diols, the protection of triols has been neglected. In this paper, we combine the protecting capability of dihydropyran and a carbonyl group in a single molecule to protect triols.

6-Benzoyl-3,4-dihydro-(2H)-pyran 1 can be conveniently prepared in large multigramme quantities. ${ }^{6}$ Addition of tert-butyl lithium (34 mmol) to 3,4-dihydro- $(2 H)$-pyran $(33 \mathrm{mmol})$ at $-20^{\circ} \mathrm{C}$ forms the vinyl anion. Cooling to $-78{ }^{\circ} \mathrm{C}$ followed by addition of $N, N$-dimethylbenzamide (31 mmol) and warming to room temperature gave a crude product ( $>95 \%$ pure) that was adequate for subsequent reactions, and could be kept in the fridge for weeks.

Initial experiments involved the reaction of $\mathbf{1}$ with glycerol and camphorsulfonic acid (CSA) in toluene under Dean and Stark conditions which gave two products, the expected trioxabicyclo[3.2.1]octane $2{ }^{7}$ and a second compound whose spectral characteristics were consistent with a 2,5,7-trioxabicyclo[2,2,2]octane. However reaction of glycerol $(2.7 \mathrm{mmol}), \mathrm{CSA}(5.5 \mathrm{mmol})$, trimethylorthoformate $(5.5 \mathrm{mmol})$ and $\mathbf{1}(5.5 \mathrm{mmol})$ in refluxing (12 h) methanol ('orthoformate' conditions) rapidly formed a single racemic crystalline triol protected product $\left(1 R, 4\left(2^{\prime}\right) S, 5 S\right)$-spiro[5-phenyl-3,6,8-trioxabicyclo[3.2.1] octane-4,2' tetrahydropyran] 2 in good yield (42\%) (Scheme 1). In the product, 2, the tetrahydropyranyl oxygen is axial relative to the 1,4-dioxane chair due to the anomeric effect, as shown in the X-ray structure (Fig. 1). Refluxing $\mathbf{2}$ in aqueous acid led to the recovery of $\mathbf{1}$.

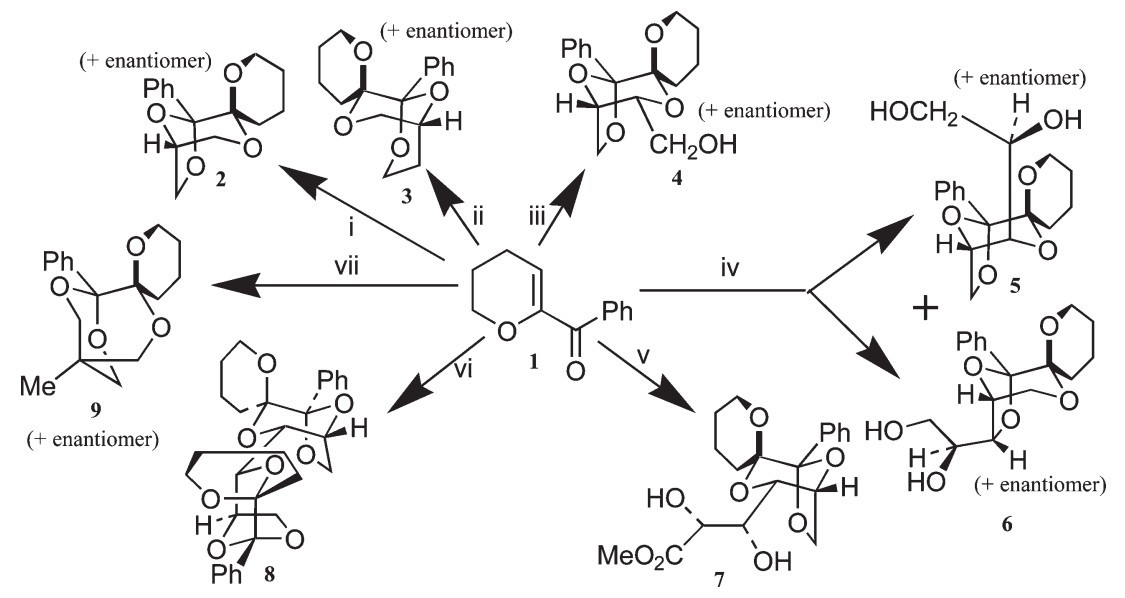

Scheme 1 Reaction of 6-benzoyl-3,4-dihydro-( $2 H)$-pyran with trihydroxy-containing compounds in refluxing methanol containing trimethylorthoformate and catalytic camphorsulfonic acid (with yields). (i) Glycerol (42\%), (ii ) racemic butane-1,2,4-triol (6.5\%), (iii) erythritol (68\%), (iv) xylitol (5 + $637 \%$ ), (v) $\delta$-gluconolactone (48\%), (vi) mannitol (39\%), and (vii) 1,1,1-tris(hydroxymethyl)ethane (5\%). 


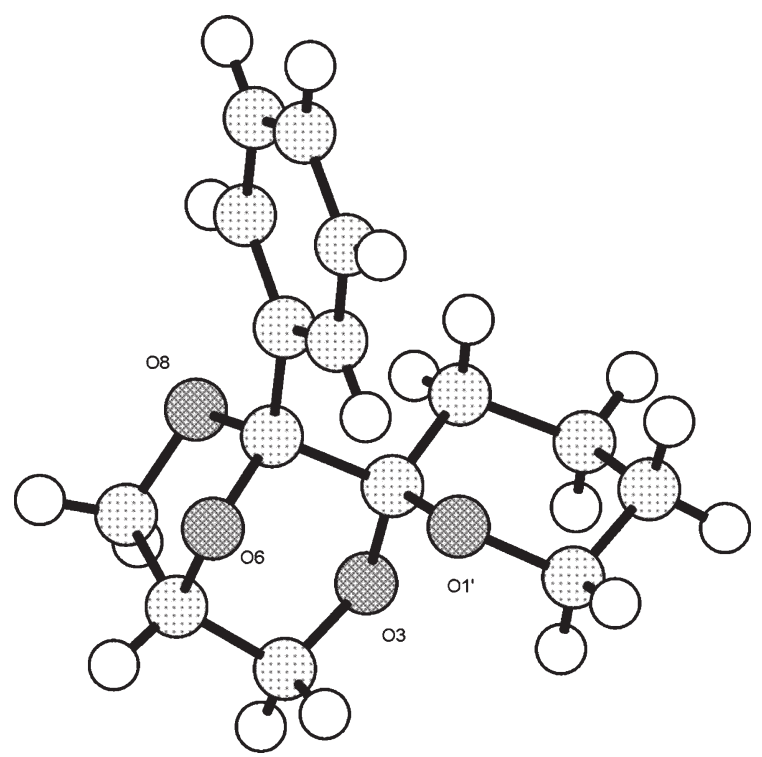

Fig. 1 X-Ray structure of 2.

Reaction of $\mathbf{1}$ with 1,2,4-butantriol under 'orthoformate' conditions led to the isolation of crystalline racemic$\left(1 R, 5 R, 8\left(2^{\prime}\right) R\right)$-spiro[1-phenyl-2, 7,9-trioxabicyclo[3.3.1]nonane$8,2^{\prime}$-tetrahydropyran] 3 in low yield (6\%) (Scheme 1, Fig. 2).

Reaction with meso-erythritol under orthoformate conditions gave one major racemic product $\mathbf{4}$ which was readily separable by flash chromatography from a second minor isomer. Derivatisation of the major isomer to the 4-nitrobenzoate and analysis by X-ray crystallography showed that the remaining hydroxymethyl group was attached to C-2. This equatorial hydroxymethyl group could be converted into the corresponding bromide $\left(\mathrm{PPh}_{3}, \mathrm{CBr}_{4}\right)$, or oxidised (Swern conditions) to the aldehyde and reacted with Grignard or Wittig reagents, or the alcohol converted into an alkene in one pot using manganese dioxide and the Wittig reagent. ${ }^{8}$ Refluxing 4 in water-THF with

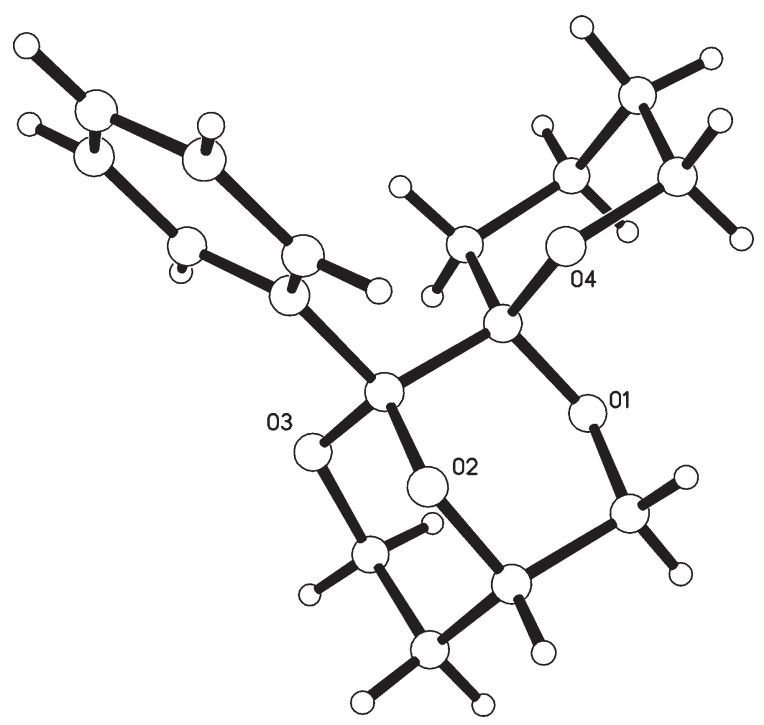

Fig. 2 X-Ray structure of 3.

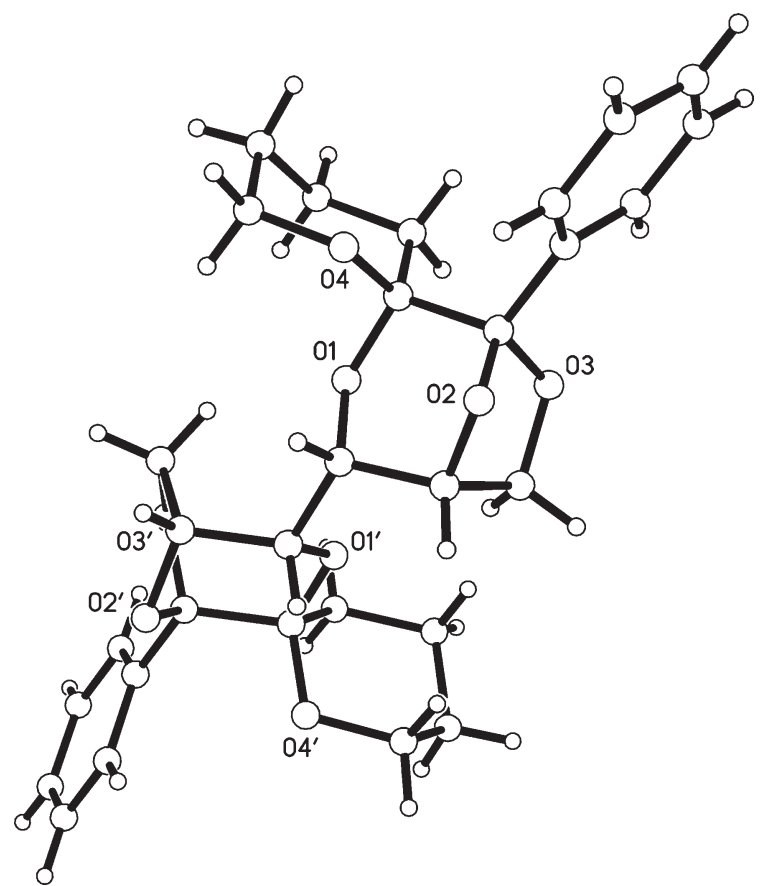

Fig. 3 X-Ray structure of 8.

CSA led to the recovery of erythritol (as the tetraacetate) in $75 \%$ yield.

Reaction of $\mathbf{1}$ with the meso-pentol xylitol under the orthoformate conditions gave two isomeric products 5 and $\mathbf{6 .}$ Derivatisation of the isomer $\mathbf{6}$ to the bis-4-nitrobenzoate followed by X-ray crystallography showed that 6 had the residual 1,2dihydroxyethyl group attached to C-7.

$\mathrm{X}$-Ray analysis of the bis-4-nitrobenzoate derivative of 7 showed that reaction of $\mathbf{1}$ with $\delta$-gluconolactone gave methoxycarbonyl 7, where reaction had occurred on the three terminal hydroxyl groups of the open chain form.

The reaction with D-(+)-mannitol under 'orthoformate' conditions gave the fully protected highly crystalline product $\mathbf{8}$ in $40 \%$ yield (Fig. 3).

Reaction with the 5-epimer of mannitol, D-sorbitol, gave a complex mixture, as did reactions attempted with molecules only containing secondary alcohols. However, reaction with 1,1,1tris(hydroxymethyl)ethane gave a product (5\%) whose spectral characteristics were consistent with the expected trioxabicyclo[3.2.2]nonane 9.

In these preliminary studies, a convenient procedure for the protection of triols has been developed, that should prove valuable in synthesis of highly functionalised polyhydroxylated natural products, desymmetrisation of meso-polyols and the synthesis of isotopically labelled compounds.

Caroline D. L. Baker, ${ }^{a}$ John Fawcett,${ }^{b}$ Christopher D. Insley, ${ }^{a}$

Derek S. Messenger, ${ }^{a}$ Claire L. Newland, ${ }^{a}$ Helen L. Overend, ${ }^{a}$

Anup B. Patel, ${ }^{a}$ Mufakhrul Shah, ${ }^{a}$ Bhavna Vara, ${ }^{a}$ Davinder Virdee ${ }^{a}$ and

Bernard J. Rawlings* $a$

${ }^{a}$ Department of Chemistry, University of Leicester, University Road,

Leicester, UK LE17RH.E-mail: bjr2@le.ac.uk;

Fax: +44 (0)116 252 3789; Tel: +44 (0)116 2522093

${ }^{b}$ Crystallography Section, Department of Chemistry, University of

Leicester, University Road, Leicester, UK LE1 7RH 


\section{Notes and references}

1 S. V. Ley, R. Downham, P. J. Edwards, J. E. Innes and M. Woods, Contemp. Org. Synth., 1995, 2, 365.

2 R. Downham, P. J. Edwards, D. A. Entwistle, A. B. Hughes, K. S. Kim and S. V. Ley, Tetrahedron: Asymmetry, 1995, 6, 2403; S. V. Ley, S. Mio and B. Meseguer, Synlett, 1996, 787; S. V. Ley, S. Mio and B. Meseguer, Synlett, 1996, 791; D. Lainé, M. Fujita and S. V. Ley, J. Chem. Soc., Perkin Trans. 1, 1999, 1639; D. Lainé, M. Fujita and S. V. Ley, J. Chem. Soc., Perkin Trans. 1, 1999, 1647.

3 G-J. Boons, P. Grice, R. Leslie, S. V. Ley and L. L. Yeung, Tetrahedron Lett., 1993, 34, 8523.

4 S. V. Ley, H. W. M. Priepke and S. L. Warriner, Angew. Chem., Int. Ed. Engl., 1994, 33, 2290; R. Lenz, S. V. Ley, D. R. Owen and S. L. Warriner,
Tetrahedron: Asymmetry, 1998, 2471; J. S. Barlow, D. J. Dixon, A. C. Foster, S. V. Ley and D. J. Reynolds, J. Chem. Soc., Perkin Trans. 1, 1999, 1627.

5 P. Grice, S. V. Ley, J. Pietruszka, H. M. I. Osborn, H. W. M. Priepke and S. L. Warriner, Chem.-Eur. J., 1997, 3, 431; M-K. Cheung, N. L. Douglas, B. Hinzen, S. V. Ley and X. Pannecoucke, Synlett, 1997 , 257; L. Green, B. Hinzen, S. J. Ince, P. Langer, S. V. Ley and S. L. Warriner, Synlett, 1998, 440.

6 R. K. Boeckman, Jr. and K. J. Bruza, Tetrahedron Lett., 1981, 37, 3997.

7 A 3,6,8-trioxabicyclo[3.2.1]octane has been reported previously: P. Calinaud and J. Gelas, Can. J. Chem., 1978, 56, 2292.

8 L. Blackburn, X. Wei and R.J. K. Taylor, Chem. Commun., 1999, 1337; X. Wei and R. J. K. Taylor, J. Org. Chem., 2000, 65, 616. 